\title{
Heritability of Spring Bloom and Fall Leaf Abscission Dates in Prunus persica
}

\author{
Paul E. Hansche \\ Department of Pomology, University of California, Davis, CA 95616
}

Additional index words. dormancy, peach

Abstract. The heritability of fall leaf abscission and spring bloom date were estimated in a peach breeding stock recently infused with genes of divergent evolutionary origin. One of the two recent progenitors of this breeding stock was evergreen. The other had a high chilling requirement. The heritability of full-bloom date in this breeding stock was estimated to be $0.60 \pm 0.08 \mathrm{SD}$, under the assumption of no outcrossing, and 0.67 $\pm 0.08 \mathrm{sD}$, under the assumption of $30 \%$ random mating. The heritability of the percentage of leaves abscised by 18 Nov. 1988 was estimated to be $0.33 \pm 0.08$, under the assumption of no outcrossing, and $0.47 \pm 0.08$, under the assumption of $30 \%$ random mating. The heritability of the percentage of leaves abscised, estimated from data collected on 14 Nov. 1989, was $0.49 \pm 0.08$, under the assumption of no outcrossing, and $0.55 \pm 0.08$, under the assumption of $30 \%$ random mating. The phenotypic correlation between date of full bloom and percentage of leaves abscised in the following November was estimated to be $0.21 ; 0.18 \mathrm{t}_{(0.05)}>0.21>0.26 \mathrm{t}_{(0.1)}$. Apparently, these traits readily could be genetically manipulated to circumvent the freeze damage that leads to susceptibility to Cytospora and related disease organisms.

Cold injury and susceptibility to Cytospora appear to be associated with peach genotypes tardy in their response to. the onset of winter or premature in their response to the onset of spring. Apparently, this and other diseases follow freeze damage of nondormant tissue (Hesse, 1975; Li, 1984; Scorza, 1984; Scorza et al., 1985). Scorza (1984) has concluded that "the short periods immediately before and following dormancy are the periods of greatest susceptibility to $\mathrm{Cy}$ tospora."

Weaver (1962) and Wenslely (1970) supplied evidence of genetic control of "rate of leaf drop " in the fall and of the correlation of this trait with the expression of "canker". Their results suggest that those cultivars that start to drop-their leaves earliest also drop them the fastest and express less canker. Thus, it appears that at least a partial solution to related disease problems may lie in developing cultivars that express earlier fall leaf abscission and a later resumption of growth in the spring.

The specific aim of this study was to establish the degree to which the observed variation in the expression of these traits in the breeding stock of the Univ. of California, Davis, can be attributed to genetic differences among seedlings. The broad objective was to determine the degree to which selection for early fall leaf abscission and latespring bloom might be effective in related breeding stocks.

The $d w$ allele that dwarfs the seedlings under study was recently inserted into this

Received for publication 26 Jan. 1990. The cost of publishing this paper was defrayed in part by the payment of page charges. Under postal regulations, this paper therefore must be hereby marked advertisement solely to indicate this fact. breeding stock through two ancestors of diverse evolutionary origin. The 'Swatow' dwarf (PI 41395), introduced in the United States in 1915 from Kiayiangchow, Swatow, China, was "evergreen" (Brooks and Olmo, 1972), The evergreen phenotype of 'Swatow' implies an evolutionary background absent of freezing winter temperatures. The 'Florey Dwarf', introduced in 1939 (from northern China), had a "high chilling requirement" (Brooks and Olmo, 1972). (The high chilling requirement of 'Florey Dwarf' implies an evolutionary background in an environment with an extended period of freezing winter temperatures).

The late Fred Anderson (who kindly supplied the Univ. of California, Davis, with the four immediate dwarf ancestors of the breeding stock under study) introduced genes from both dwarfs into his peach breeding stock at Merced, Calif., $\approx 40$ years ago (Hansche, 1986). He then backcrossed the resulting $\mathrm{F}_{2}$ dwarf hybrids to standard peach and nectarine genotypes two or three times while selecting for fruit quality traits.

The data for the current study were collected from 1329 dwarf seedlings comprising 77 dwarf $\mathrm{F}_{3}$ families, averaging $\approx 17$ seedlings per family. These families were derived from the open pollination of 72 dwarf $\mathrm{F}_{2}$ segregants (1 dwarf :3 tall) selected on the basis of fruit quality. These dwarf $F_{2}$ segregants were derived from the open pollination of heterozygous $(D w / d w) \mathrm{F}_{1}$ progeny of controlled crosses between four dwarf $(d w /$ $d w$ ) genotypes (obtained from F. Anderson) and nine standard $(D w / D w)$ genotypes (from UC Davis' peach breeding stock). The crosses were made solely on the basis of fruit quality.

The dwarf $\mathrm{F}_{3}$ seedlings were planted 0.3 $\times 1.2 \mathrm{~m}$ apart at Davis, Calif. Siblings were planted adjacently within rows. Planting siblings adjacently minimizes the effects of local environmental variability on within-family variability. Consequently, to the extent that such effects existed, heritability estimates are biased upward. Full-bloom date (Julian calendar) was estimated in the spring of the 3rd year of seedling growth (1989) according to the method of Hansche et al. (1972). Using a scale of 0 to 20 , the percentage of the canopy abscised (percent leaf drop) was estimated 18 Nov. 1988 and again 14 Nov. 1989.

The total phenotypic variance of measurements, VP, was broken into "between" and "within" family components, $\mathrm{v}_{\mathrm{b}}$ and VW, respectively, via the procedure outlined by Snedecor (1956) for a one-way random effects analysis of variance with nested samples of unequal size (Model II).

The between-family component, $\mathrm{v}_{\mathrm{b}}$, estimates $[(1+F) / 2]\left(V_{a}\right)+\left[(1+F)^{2} / 4\right]\left(V_{d}\right)$, where families comprised full-sibs (Kempthorne, 1957). Here, $V_{a}$ and $V_{d}$ are the components of genetic variance resulting from additive and dominant statistical effects of genes, and $\mathrm{F}$ is the inbreeding coefficient of $\mathrm{F}_{3}$ seedlings. Consequently, $\mathrm{V}_{\mathrm{b}}$ can be used to estimate narrow-sense heritability, $\mathrm{h}^{2}=$ $\mathrm{V}_{\mathrm{a}} / \mathrm{V}_{\mathrm{p}}$, where the inbreeding coefficient $\mathrm{F}$ is known and $\mathrm{V}_{\mathrm{d}}=0$. The heritability estimator used, $\mathrm{H}^{2}=\left(2 /(1+\mathrm{F}) \mathrm{v}_{\mathrm{b}}\left(\mathrm{v}_{\mathrm{b}}+\mathrm{v}_{\mathrm{w}}\right)\right.$ $=\left(\mathrm{V}_{\mathrm{a}} / \mathrm{v}_{\mathrm{p}}\right)$, ignores the effects of dominance variance, i.e., the contribution of the term $\left[(1+F)^{2} / 4\right]\left(V_{d}\right)$ to $v_{b}$ of full-sibs. The assumption here is that the effects of dominance would not have a significant effect on the result. In any case, $\mathrm{H}^{*}$ provides a conservative estimate of broad sense heritability or a slightly inflated estimate of narrow sense heritability.

The effects of inbreeding relevant to the estimation of heritabilities were those accrued from consanguineous matings among $F_{1}$ and $F_{2}$ seedlings. For the purposes of these heritability estimates, the inbreeding coefficient, $\mathrm{F}$, among $\mathrm{F}_{1}$ seedlings was assumed to be 0 .

Estimates of self-pollination in peach vary between $70 \%$ and 95\% (Hesse, 1975; Fogle, 1977; Miller et al., 1989). This suggests that $5 \%$ to $30 \%$ of the seedlings within families derived from seed from a single female parent (tree) are half-, instead of full-, sibs. It also implies that the average inbreeding coefficient pertaining to these $\mathrm{F}_{3}$ families is somewhat less than $\mathrm{F}=1 / 2+(1 / 2)^{2}=$ 0.75 , which would result from two generations of exclusive self-pollination.

The average coefficient of inbreeding pertaining to $\mathrm{F}_{3}$ seedlings in a population that is $70 \%$ self-pollinated and $30 \%$ randomly pollinated can be calculated as follows.

$\mathrm{F}_{2} \mathrm{~s}: 70 \%$ of the $\mathrm{F}_{2}$ seedlings would have an $\mathrm{F}$ of 0.5 due to self-pollination of their parents; $30 \%$ would have an $\mathrm{F}$ of 0 due to parental outcrossing.

$\mathrm{F}_{3} \mathrm{~s}: 70 \%$ of the $\mathrm{F}_{2}$ parents that have an $\mathrm{F}$ value of 0.5 are expected to self-pollinate. This would generate an $\mathrm{F}$ of 0.75 among $49 \%$ of the $\mathrm{F}_{3}$ seedlings. Of the $\mathrm{F}_{2}$ parents that have an $\mathrm{F}$ value of $0.5,30 \%$ are ex- 
petted to be randomly pollinated. This would lead to an $\mathrm{F}$ of 0.5 among $21 \%$ of the $\mathrm{F}_{3}$ seedlings. Of the $\mathrm{F}_{2}$ parents that have an $\mathrm{F}$ value of $0,70 \%$ are expected to self-pollinate. This would generate an $\mathrm{F}$ of 0.5 among $21 \%$ of the $\mathrm{F}_{3}$ seedlings. Of the $\mathrm{F}_{2}$ parents that have an $\mathrm{F}$ value of $0,30 \%$ are expected to be randomly pollinated. This would lead. to an $\mathrm{F}$ of 0 among $9 \%$ of the $\mathrm{F}_{3}$ seedlings. Thus, the average coefficient of inbreeding among the $\mathrm{F}_{3}$ seedlings would be $\mathrm{F}=$ $(0.49)(0.75)+(0.21)(0.5)+(0.21)(0.5)$ $+(0.09)(0)=0.58$.

The effect of open pollination on the heritability estimator $\mathrm{H}_{2}=[2 /(1+\mathrm{F})],\left(\mathrm{v}_{\mathrm{b}}\right) /\left(\mathrm{v}_{\mathrm{b}}\right.$ $+\mathrm{v}_{\mathrm{w}}$ ), which is based on the assumption of full-sib families, is to bias it downward, because the between-family variation generated by half-sibs is only $(1 / 4) \mathrm{V}_{\mathrm{a}}$, rather than $(1 / 2) \mathrm{V}_{\mathrm{a}}$, which pertains to full-sibs. Furthermore, outcrossing inflates VW while reducing $\mathrm{V}_{\mathrm{b}}$ (Kempthorne, 1957). The standard deviations of $\mathrm{H}^{2}$ estimates were calculated according to the relationship of Falconer (1981), $\mathrm{V}_{\mathrm{h}} 2=16\left(\mathrm{~h}^{2}\right) / \mathrm{T}$, where $\mathrm{T}$ is the total number of seedlings. The confidence intervals about estimated correlations were calculated via Fisher's z statistic (Snedecor, 1956).

Bloom date. The mean full-bloom date of the $\mathrm{F}_{3}$ dwarf breeding stock, estimated to be the 66th Julian day in 1988 , is $\approx 6$ days earlier than that of UC Davis' standard breeding stock from which it was derived (Hansche et al, 1972). This may be a reflection of the dwarf breeding stock's evergreen 'Swatow' ancestry.

The phenotypic standard deviation (SD) of full-bloom date in this dwarf breeding stock is 5 days, almost twice that of the standard breeding stock from which it was derived; there SD, = 3 days (Hansche et al., 1972). As a-consequence of this increased variability, the range of the dwarf seedling bloom date measures completely overlapped that of the standard breeding stock analyzed, in spite of the fact that its mean full-bloom date was 6 days earlier.

The large increase in bloom date variability, attributable to genes carried by the dwarf progenitors of this breeding stock, is consistent with the previously estimated increases in the variance of measures of fruit size, percent soluble solids content, and amount of fruit blush in this dwarf breeding stock (Hansche, 1978; Hansche et al., 1972). This increase in genetic variance supports the oftenexpressed notion that present standard peach breeding stocks in the Western Hemisphere comprise but a very small, highly selected sample of the genetic variation existing in this species (Hesse, 1975; Miller et al., 1989; Scorza et al., 1985). The increase also is consistent with" the relatively diverse evolutionary history of the dwarf progenitors of this breeding stock (Brooks and Olmo, 1972).

The within- and between-family components of bloom-date variance were estimated to be $\mathrm{v}_{\mathrm{w}}=11.33$ and $\mathrm{v}_{\mathrm{b}}=12.67$, The inbreeding coefficient, $\mathrm{F}$, expected from two generations of $100 \%$ selfing would be 0.75 . Thus, $\mathrm{H}^{2}=[2 /(1+0.75)]\left(\mathrm{v}_{\mathrm{b}} / \mathrm{v}_{\mathrm{p}}\right)=0.60$ \pm 0.08 . Under the assumption of two gen- erations of $70 \%$ selfing and $30 \%$ random mating, $\mathrm{F}=0.58$ (see above) and the heritability estimate is $\mathrm{H}^{2}=[2 /(1+0.58)]\left(\mathrm{v}_{\mathrm{b}} /\right.$ $\mathrm{VP})=0.67 \pm 0.08$

These estimates are $50 \%$ to $80 \%$ higher than estimated in the standard breeding stock from which this dwarf breeding stock was derived; there the heritability was estimated to be $0.39 \pm 0.03$ (Hansche et al., 1972).

The increased heritability is apparently a direct reflection of the increased genetic variance, alluded to above, introduced into this population through its dwarf progenitors. This high heritability is more in line with the $\mathrm{h}^{2}$ estimates found in UC Davis' breeding stocks of the related species Prunus avium and $P$. domestics $(1.0 \pm 0.06$ and $0.86 \pm 0.19$, respectively) than with the estimate in the ancestral standard peach breeding stock (Hansche et al., 1966, 1975). This finding further supports the contention of Hesse (1975) and of Scorza et al. (1985) that peach germplasm in the United States is relatively homogeneous.

The high heritability of full-bloom date indicates that it could be genetically manipulated in this population over a wide range of dates. For example, since $R_{S D}=i h^{2}$, where $R_{S D}$ is the response to selection (in standard deviations) and $\mathrm{i}$ is the selection intensity, a selection intensity of two standard deviations beyond the mean bloom date would be expected to delay the mean full-bloom date of progeny by nearly a week in a single selection cycle; i.e., $\mathrm{R}=(2)(0.68)=1.36 \mathrm{sD}$ $=6.7$ days; this could be a slight over-estimate of actual rate of gain, since $\mathrm{H}^{*}$ may be a slight over-estimate of $h^{2}$.

Leaf abscission. Only 14\% of the leaves were estimated to remain on the average seedling on 18 Nov. 1988. The variance in the percentage of leaves abscised, $\mathrm{v}_{\mathrm{p}}$, was estimated to be 14 . The within- and betweenfamily components of this variance were estimated to be $\mathrm{v}_{\mathrm{w}}=8.8$ and $\mathrm{v}_{\mathrm{b}}=5.2$, respectively; 3170 of the leaves were estimated to remain on the average seedling on 16 Nov. 1989. VP was estimated to be 9 . The estimates in 1989 were $\mathrm{VW}=5.1$ and $\mathrm{v}_{\mathrm{b}}=3.9$.

The heritabilities estimated from data collected on 18 Nov. 1988 were $\mathrm{H}^{2}=0.33$, under the assumption of no outcrossing, and 0.47 , under the assumption of $30 \%$ random mating. [The standard deviations of all $\mathrm{H}^{2}$ estimates were calculated according to the relationship of Falconer $(1981), \mathrm{v}_{\mathrm{h}}{ }^{2}=16\left(\mathrm{~h}^{2}\right) /$ $\mathrm{T}$, where $\mathrm{T}$ is the total number of seedlings. $\mathrm{T}=1329$ for all $\mathrm{Hz}$ estimates here, and thus the $\mathrm{v}_{\mathrm{H}}{ }^{2}$ were all \&0.08 when rounded to two decimal places.] The heritabilities estimated from data collected on 14 Nov. 1989 were $\mathrm{H}^{*}=0,49$, under the assumption of no outcrossing, and 0.55 , under the assumption of $30 \%$ random mating.

These results suggest that $40 \%$ to $50 \%$ of the observed variability in the percentage of leaves abscised on a single day in November in this breeding stock has a genetic basis. This contention is consistent with subjective observations of gross differences between families in this seedling plot. It also suggests that selection based on this relatively crude subjective measure would be nearly as effective in modifying the expression of this trait as it would be in modifying full-bloom date. More precise measures of date and rate of leaf abscission would likely have even higher heritabilities.

The correlation between the percentage of canopy abscised by 18 Nov. and full-bloom date the following spring was estimated to be $0.11 ; 0.7 \mathrm{t}_{(0.05)}>0.11>0.16 \mathrm{t}_{(0.05)}$. The correlation between full-bloom date and the percentage of the canopy abscised by the following 16 Nov. was estimated to be 0.21 ; $0.16 \mathrm{t}_{(0.05)}>0.21>0.26 \mathrm{t}_{(0.05)}$. This relationship suggests that selection for early leaf drop and for late spring bloom may have a slightly positive synergistic effect on lengthening the dormant period. This fortuitous result appears to be consistent with evolutionary expectations; i.e., species in a cold climate would be blooming later and abscising leaves earlier than those in a warm climate.

The correlation between the measures of late spring bloom and early leaf abscission prompted estimation of the heritability of the compound trait (full-bloom date Spring 1989 with percent leaf abscission in Fall 1989) that is a measure, albeit crude, of the length of the period of active growth. The heritability of this compound measure was estimated to be 0.37 , under the assumption of no outcrossing, and 0.49 , under the assumption of $30 \%$ random mating.

These results quantify our subjective observations of gross differences among families in this breeding stock with respect to the date of full bloom and of leaf drop. Further, they indicate that selection for cultivars that drop their leaves relatively early in the fall and bloom relatively late in the spring would be effective, i.e., these data suggest the length of the dormant period in such populations could be genetically manipulated with relative ease.

\section{Literature Cited}

Brooks, R.M. and H.P. Olmo. 1972. Register of new fruit and nut varieties. Univ. of California Press, Berkeley.

Falconer, D.S. 1981. Introduction to quantitative genetics. 2nd ed. Longman, New York.

Fogle, H.W. 1977. Self-pollination and its implications in peach improvement. Fruit Var. J. 31:74-75.

Hansche, P.E. 1986. Heritability of fruit quality traits in peach and nectarine breeding stocks dwarfed by the $d w$ gene. HortScience 21:11931195.

Hansche, P. E., V. Beres, and R.M. Brooks. 1966. Heritability and genetic correlation in sweet cherry. J. Amer. Soc. Hort. Sci. 88:173-183.

Hansche, P. E., C.O. Hesse, and V. Beres. 1972. Estimates of genetic and environmental effects of several traits in peach. J. Amer. Soc. Hort Sci. 97:76-79.

Hansche, P. E., C.O. Hesse, and V. Beres. 1975. Inheritance of fruit size, soluble solids and ripening date in Prunus domestica CV. Agen. J. Amer. Soc. Hort. Sci. 100:522-524.

Hesse, C.O. 1975. Peaches, p. 285-335. In: J. Janick and J.N. Moore (eds.). Advances in fruit breeding. Purdue Univ. Press, West Lafeyette, Ind. 
Kempthorne, O. 1957. An introduction to genetic statistics. Wiley, New York.

Li, Z. 1984. Peach germplasm and breeding in China. HortScience 19(3):348-351.

Miller, P. D., D.E. Parfitt, and S.A. Weinbaum. 1989. Outcrossing in peach. HortScience 24:359360.

Scorza, R.S. 1984. Peach tree decline in relation to peach germplasm. 1984 Stone Fruit Tree Decline Workshop Proc. U.S. Dept. Agr./Agr. Res. Serv. p. 191-195.

Scorza, R., S.A. Mehlenbacher, and G.W. Lightner. 1985. Inbreeding and coancestry of freestone peach cultivars of the eastern United States and implications for peach germplasm improvement. J. Amer. Soc. Hort. Sci. 110:547-552.
Snedecor, G. 1956. Statistical methods. 5th ed. Iowa State College Press, Ames.

Weaver, G.M. 1962. A relationship between the rate of leaf abscission and perennial canker in peach varieties. Can. J. Plant Sci. 43:365-369.

Wensley, R.N. 1970. Innate resistance of peach to perennial canker. Can. J. Plant Sci. 50:339345. 